\title{
Hemodynamic performance of an unstented xenograft mitral valve substitute
}

\author{
Tomasz A. Timek, MD \\ David T. Lai, FRACS ${ }^{a}$ \\ Frederick A. Tibayan, $\mathrm{MD}^{\mathrm{a}}$ \\ Paul Dagum, MD, PhD \\ George T. Daughters, MS ${ }^{\mathrm{a}, \mathrm{b}}$ \\ David Liang, MD, $\mathrm{PhD}^{\mathrm{C}}$ \\ Neil B. Ingels, Jr, PhD ${ }^{\mathrm{a}, \mathrm{b}}$ \\ D. Craig Miller, $M^{\mathrm{a}}$
}

From the Department of Cardiovascular and Thoracic Surgery a and the Division of Cardiovascular Medicine, ${ }^{\mathrm{c}}$ Stanford University School of Medicine, Stanford, Calif, and the Laboratory of Cardiovascular Physiology and Biophysics, ${ }^{\text {b }}$ Research Institute of the Palo Alto Medical Foundation, Palo Alto, Calif.

Supported by grants HL-29589 and HL67025 from the National Heart, Lung, and Blood Institute and a contract from Medtronic Heart Valve Division, Minneapolis, Minn. Drs Timek, Tibayan, Dagum, and Lai are Carl and Leah McConnell Cardiovascular Surgical Research Fellows. Drs Timek and Dagum were supported by NHLBI Individual Research Service Awards HL-10452 and HL-10000. Dr Timek is also a recipient of the Thoracic Surgery Foundation Research Fellowship Award. Dr Lai was supported by a fellowship from the American Heart Association, Western States Affiliate.

Read at the Twenty-seventh Annual Meeting of The Western Thoracic Surgical Association, San Diego, Calif, June 20-23, 2001

Received for publication June 28, 2001; revisions requested Sept 19, 2001; revisions received Jan 4, 2002; accepted for publication Feb 18, 2002.

Address for reprints: D. Craig Miller, MD, Department of Cardiovascular Surgery, Falk Cardiovascular Research Center, Stanford University School of Medicine, Stanford, CA 94305-5247 (E-mail: dcm@ stanford.edu).

J Thorac Cardiovasc Surg 2002;124:541-52

Copyright ( $(2) 2002$ by The American Association for Thoracic Surgery

$0022-5223 / 2002 \$ 35.00+0 \quad \mathbf{1 2 / 6 / 1 2 4 3 9 0}$

doi:10.1067/mtc.2002.124390
Objective: Stentless mitral xenografts offer potential clinical benefits because they mimic the normal bileaflet mitral valve. How best to implant them and their hemodynamic performance and durability, however, remain unknown.

Methods: A stentless porcine mitral xenograft valve (Medtronic physiologic mitral valve) was implanted in 7 sheep with papillary muscle sewing tubes attached with transmural left ventricular sutures. Radiopaque markers were inserted on the leaflets, annular cuff, papillary tips, and left ventricle. After $10 \pm 5$ days, the animals were studied with biplane videofluoroscopy to determine 3-dimensional marker coordinates at baseline and during dobutamine infusion. Transesophageal echocardiography assessed mitral regurgitation and valvular gradients. Mitral annular area was calculated from the annular markers. Physiologic mitral valve leaflet and annular dynamics were compared with 8 native sheep valves.

Results: Average mitral regurgitation grade at baseline was $1.2 \pm 1.0$ (range, 0-4), and the mean transvalvular pressure gradients were $3.6 \pm 1.3$ and $6.2 \pm 2.2 \mathrm{~mm} \mathrm{Hg}$ during baseline and dobutamine infusion, respectively. Xenograft mitral annular area contraction throughout the cardiac cycle was reduced (6\% $\pm 6 \%$ vs $13 \% \pm 4 \%$ for physiologic mitral valve and control valve, respectively; $P=.03$ ). Physiologic mitral valve leaflet geometry during closure differed from the native valve, with the anterior leaflet being convex to the atrium and with little motion of the posterior leaflet. Three animals survived more than 3 months; good healing of the annular cuff and papillary muscle tubes was demonstrated.

Conclusion: This stentless xenograft mitral valve substitute had low gradients at baseline and during stress conditions early postoperatively, with mild mitral regurgitation. Preliminary analysis of healing characteristics appeared favorable at 3 months. Additional studies are needed to determine long-term xenograft mitral valve performance and resistance to calcification.

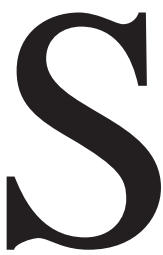

tentless mitral xenografts might offer potential clinical benefits because the durability of all currently available porcine semilunar bioprostheses in the high-stress mitral position is suboptimal compared with that in the aortic position. A xenograft mitral bioprosthesis is naturally bileaflet, which would better mimic nature's design for the atrioventricular position; theoretically, this should translate into enhanced clinical durability (freedom from structural valve dysfunction). The hemodynamic performance, durability, and technical feasibility of implanting unstented mitral xenografts, however, still need to be determined. Limited clinical experience 
with unstented mitral prostheses has been reported periodically in the literature since the experimental inception of mitral homografts almost 40 years ago. ${ }^{1-3}$ Although early results of homograft mitral valve replacement in patients were disappointing after structural valve dysfunction, ${ }^{4,5}$ advances in surgical techniques ${ }^{6}$ and improved understanding of mitral physiology have spurred a renewed clinical interest in stentless mitral valve substitutes..$^{7-9}$

The theoretic advantages of stentless mitral homografts and xenografts over traditional stented bioprostheses include better hemodynamic performance, lower thrombogenicity, resistance to infection, preservation of valvular-ventricular continuity ${ }^{8}$ (which helps maintain left ventricular [LV] systolic pump function $^{10,11}$ ), and possibly enhanced structural durability. The availability of suitable mitral homograft valves is limited, however, and valve implantation techniques are demanding and require considerable experience. Although good results have been obtained in a few centers with mitral unstented homografts ${ }^{12}$ and xenografts, ${ }^{13}$ consistent clinical outcomes have not been universal. ${ }^{14,15}$ The heterogeneity of papillary muscle (PM) anatomy in the human heart ${ }^{16,17}$ also complicates homograft implantation techniques.

Porcine xenografts offer the advantage of plentiful availability and more consistent subvalvular anatomy, but their hemodynamic performance and optimal implantation technique are not known. We have previously reported on the feasibility of implanting a stentless porcine mitral xenograft (Medtronic physiologic mitral valve [PMV]) in a sheep model and its immediate postoperative hemodynamic performance (acute open-chest preparation). ${ }^{18}$ In the current experiment, we placed radiopaque markers on this porcine mitral xenograft to evaluate valvular dynamics and gradients and leaflet 3-dimensional (3-D) motion at rest and during inotropic stimulation 10 days after implantation.

\section{Methods}

The PMV stentless porcine xenograft was implanted in 22 adult sheep on cardiopulmonary bypass (CPB). Seven animals survived beyond 24 hours and were subsequently evaluated at 6 to 19 days (mean, $10 \pm 5$ days) postoperatively under conscious, closed-chest conditions. Mitral annular and leaflet dynamics were compared with those of a control group of 8 sheep that underwent marker implantation only and were subsequently studied after 7 to 10 days (mean, $7 \pm 1$ days).

\section{Porcine Mitral Xenograft}

Porcine mitral valves were harvested from adult pig hearts and removed with the anulus, leaflets, chordae, and PMs intact by Medtronic Heart Valve Division (Minneapolis, Minn). The PMV design has been modified since our earlier preliminary experiment, ${ }^{18}$ including UltiFix fixation, a pliable annular sewing cuff of UltiFix-preserved porcine pericardium, and Dacron velour sewing tubes attached to each PM head. The valve and subvalvular apparatus were fixed in UltiFix solution, a nonglutaraldehyde process that forms amide bonds with carbodiimide cross-linking in the presence of coupling agents. Tissue cross-linking is as good as glutaraldehyde on the basis of shrinkage temperature and enzymatic digestion analysis. It is biocompatible and resists calcification, as demonstrated in both the rat subdermal and juvenile sheep models. ${ }^{19}$ The anatomy of the porcine mitral valve is different than that in sheep or human subjects: The orientation of the pig PMs is approximately $180^{\circ}$ to each other, and the areas and heights of the porcine anterior and posterior leaflets are approximately equal. PMV size was selected on the basis of animal weight (PMV to native valve size correlations derived from previous acute, openchest experiments), and 8 miniature radiopaque markers were sewn around the anulus of the xenograft: 1 on each PM head, 4 on the central portion of the anterior leaflet, and 2 on the central portion of the posterior leaflet (Figure 1,A).

\section{Surgical Procedure}

The techniques for marker ${ }^{20}$ and porcine xenograft ${ }^{18}$ implantation have been described previously. The animals were premedicated with ketamine $(25 \mathrm{mg} / \mathrm{kg}$ administered intramuscularly), and anesthesia was induced with sodium thiopental $(6.8 \mathrm{mg} / \mathrm{kg}$ administered intravenously) and maintained with inhalational isoflurane (1\%-2.2\%). Eight tantalum myocardial markers (inner diameter, $0.8 \mathrm{~mm}$; outer diameter, $1.3 \mathrm{~mm}$; length, $1.5-3.0 \mathrm{~mm}$ ) were inserted beneath the LV epicardial surface along 4 equally spaced longitudinal meridians, and an additional marker was placed at the LV apex. Subsequently, the anterior ovine mitral leaflet was excised, leaving 2 to $3 \mathrm{~mm}$ remaining along the anulus. The posterior mitral leaflet and its chordal attachments were left intact to provide more tissue for suturing of the xenograft anulus, especially in the commissural areas. Mitral xenografts were sized on the basis of animal weight. The size was based on prior short-term experiments in which the intertrigonal distance and the area of the anterior leaflet of the native valve were measured to choose the appropriate size for the prosthesis. ${ }^{18}$ In the current series we selected the appropriately sized prosthesis before CPB to allow the markers to be sewn to the xenograft before implantation. The rinsed xenograft ( 3 at $29 \mathrm{~mm}, 2$ at $31 \mathrm{~mm}$, and 2 at $35 \mathrm{~mm}$ ) was placed within the LV cavity in an anatomic orientation, and the length of the PM sewing tubes was assessed. In most cases the Dacron tubes were shortened to allow the PM tips to be positioned within the ventricle at a level sufficiently apical to prevent leaflet prolapse (which depended on the size of the ventricle and the length of the sewing tubes) and sutured to the LV wall at the appropriate level with the PMV anterior PM located near the recipient's native anterolateral PM and the PMV posterior PM being sutured adjacent to the recipient's posteromedial $\mathrm{PM}$, such that they were approximately $180^{\circ}$ opposite to each other, rather than the normal $120^{\circ}$ to $150^{\circ}$ angle between the sheep's native PMs. ${ }^{18}$ Two transmural 1-0 braided polyester horizontal mattress sutures secured each PM sewing tube, with the sutures tied over a Teflon felt pledget on the LV epicardial surface. Care was taken to avoid coronary arteries. By using two 4-0 polypropylene sutures starting at the fibrous trigones, the PMV xenograft sewing ring was sutured to the native anulus in running fashion (Figure 1, B). There was size mismatch for the two $35-\mathrm{mm}$ valves when the native anulus was smaller, even when large sheep were used $(>90 \mathrm{~kg})$. This mismatch was addressed by means of annular plication. The animal was rewarmed, the atriotomy was closed, the crossclamp was removed, 

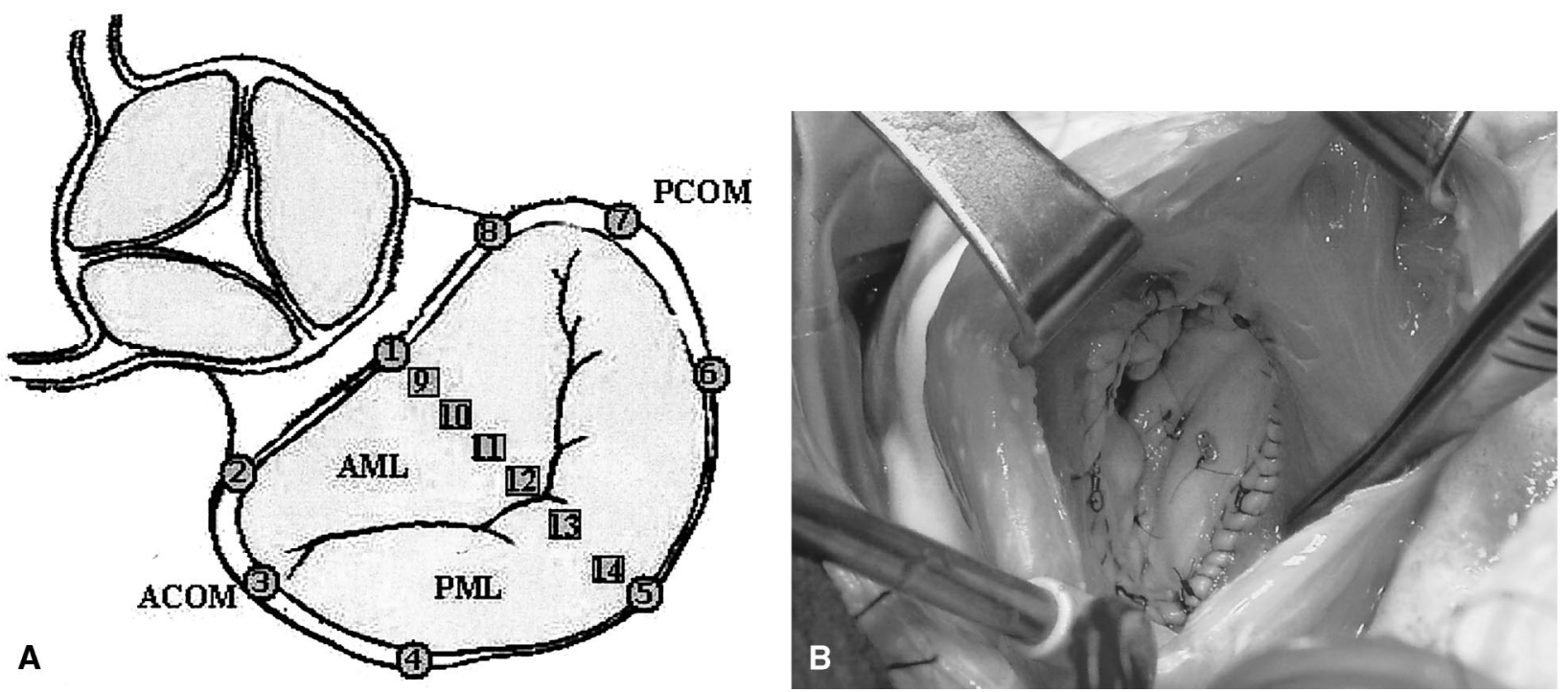

Figure 1. A, Schematic representation of the annular and leaflet marker array used in the study. Annular markers are shown as circles, and leaflet markers are shown as squares. ACOM, anterior commissure; PCOM, posterior commissure. $B$, Intraoperative photograph of the implanted stentless PMV bioprosthetic mitral valve. AML with attached gold markers is visible through the valve orifice.

and the animal was weaned from bypass. A micromanometer pressure transducer (PA4.5-X6; Konigsberg Instruments, Inc, Pasadena, Calif) was placed in the LV chamber through the apex. Epicardial echocardiography was used to assess immediate valve function and transvalvular gradients. After extubation, the animals recovered in the experimental animal cardiac surgical intensive care unit. Eight control animals from an earlier experiment had markers implanted on the left ventricle and the native ovine valve in the same array as for the xenograft (Figure 1, $A$ ).

\section{Experimental Protocol}

After $10 \pm 5$ days' recovery, the sheep were sedated with propofol (150-300 $\mathrm{mg} / \mathrm{h}$ ) and diazepam (5-mg intravenous bolus as needed) and intubated. Intravenous esmolol infusion (20-50 $\mu \mathrm{g} \cdot \mathrm{kg}^{-1}$. $\min ^{-1}$ ) was used to minimize reflex sympathetic responses. A Swan-Ganz catheter was placed through the left internal jugular vein for measurement of cardiac output. Simultaneous biplane videofluoroscopy, hemodynamic data recordings, and transesophageal pulse-wave and color Doppler echocardiography were conducted under 2 experimental conditions in the PMV group: (1) baseline and (2) inotropic stimulation with dobutamine $(10 \mu \mathrm{g}$. $\left.\mathrm{kg}^{-1} \cdot \min ^{-1}\right)$. In the control animals only baseline data were obtained. The PMV animals were subsequently allowed to recover and then electively killed at 3 to 4 months after valve implantation. All animals received humane care in compliance with the "Principles of Laboratory Animal Care" formulated by the National Society for Medical Research and the "Guide for the Care and Use of Laboratory Animals" prepared by the Institute of Laboratory Animal Resources, National Research Council, and published by the National Academy Press, revised 1996. This study was approved by the Stanford Medical Center Laboratory Research Animal Review Committee and conducted according to Stanford University policy.

\section{Data Acquisition}

Images were acquired with the animal in the right lateral decubitus position with a Philips Optimus 2000 biplane Lateral ARC 2/Poly DIAGNOST C2 system (Phillips Medical Systems, North America Company, Pleasanton, Calif) with the image intensifier in the 9-inch fluoroscopic mode. Data from 2 radiographic views were digitized and merged to yield 3-D coordinates for each of the radiopaque markers every 16.7 seconds by using custom-designed software. ${ }^{21}$ Ascending aortic pressure, LV pressure, and electrocardiographic voltage signals were digitized and recorded simultaneously during data acquisition.

\section{Data Analysis}

Two steady-state beats from each animal in the control and PMV groups were averaged and defined as control and PMV data, respectively. During each cardiac cycle, the time of end-systole was defined as the videofluoroscopic frame containing the point of peak rate of $\mathrm{LV}$ pressure fall $(-\mathrm{dP} / \mathrm{dt})$, whereas the time of end-diastole was defined as the videofluoroscopic frame containing the peak of the electrocardiographic $\mathrm{R}$ wave. Instantaneous LV volume was calculated from the epicardial LV markers with the use of a space-filling multiple tetrahedral volume method for each frame (ie, every $16.7 \mathrm{~ms}$ ). ${ }^{22}$ Although myocardial volume is included in this calculation of LV volume (thereby overestimating end-diastolic LV volume), this parameter accurately reflects relative changes in LV chamber size.

\section{Mitral Annular and Leaflet Dynamics}

Mitral annular area (MAA) was calculated as the sum of multiple triangular areas, each from 2 adjacent annular markers and the 3-D centroid $^{20}$ of the annular markers (Nos. 1-8; Figure 1, A). MAA contraction ( $\triangle \mathrm{MAA})$ was determined as the percentage change 
TABLE 1. Hemodynamics

\begin{tabular}{lccc}
\hline & Control & PMV & P value \\
\hline HR (beats/min) & $99 \pm 8$ & $109 \pm 20$ & .2 \\
$\mathrm{dP} / \mathrm{dt}_{\text {MAX }}(\mathrm{mm} \mathrm{Hg})$ & $1455 \pm 287$ & $1322 \pm 397$ & .5 \\
$\operatorname{LVP} \mathrm{MAX}_{\mathrm{Mm} \mathrm{Hg})}$ & $119 \pm 13$ & $108 \pm 9$ & .09 \\
$\mathrm{EDV}(\mathrm{mL})$ & $155 \pm 28$ & $176 \pm 25$ & .15 \\
$\mathrm{ESV}(\mathrm{mL})$ & $119 \pm 26$ & $137 \pm 15$ & .14 \\
$\mathrm{SV}(\mathrm{mL})$ & $36 \pm 7$ & $40 \pm 12$ & .5
\end{tabular}

Data are shown as mean \pm SD. $P$ value by means of $t$ test for independent observations.

$H R$, Heart rate; $d P / d t_{M A X}$ maximum positive rate of change of LV pressure; $L V P_{M A X}$, maximum systolic LV pressure; EDV, LV end-diastolic volume; ESV, LV end-systolic volume; $S V$, stroke volume.

throughout the cardiac cycle from maximum to minimum area. A plane was fitted to the posterior annular markers (Nos. 3-7; Figure $1, A$ ) by using least-squares estimation to quantify the amount of annular folding or tilting during the cardiac cycle. Septal (anterior) annular elevation was defined as the vertical distance of marker 1 (saddle-horn marker; Figure 1, $A$ ) from that plane.

Anterior mitral leaflet (AML) and posterior mitral leaflet (PML) lengths were calculated as the sum of individual segments defined by the implanted markers on the central portion of each leaflet. Angular position of the anterior leaflet edge was calculated throughout the cardiac cycle as the angle $\left(\varphi_{\mathrm{AML}}\right)$ between the anterior leaflet edge marker (No. 12) and the midseptal (No. 1) and midlateral (No. 5) anulus. Posterior leaflet edge angular position $\left(\varphi_{\mathrm{PML}}\right)$ was calculated in a similar fashion. For 3-D reconstruction of annular and leaflet shape, an internal right-handed Cartesian coordinate system was defined with the origin located at the midseptal anulus marker (No. 1), the positive $\mathrm{X}$-axis directed toward the midlateral anulus (marker No. 5), the positive Y-axis directed toward the LV apex, and the positive $\mathrm{Z}$-axis directed toward the posterior commissure. The midseptal anulus was chosen as the origin because it is at the center of the fibrous anulus and represents an anatomic landmark that is relatively stable in laboratory coordinates.

\section{Statistical Analysis}

All data are reported as means $\pm 1 \mathrm{SD}$, unless otherwise stated. Hemodynamic and marker-derived data from 2 consecutive steady-state beats were aligned at end-diastole $(\mathrm{t}=0)$, and data from the 2 beats were averaged over all animals in each group. The data (time aligned at end-diastole) were analyzed from 20 frames before to 20 frames after end-diastole, thereby allowing evaluation of the studied variables over the entire cardiac cycle. Data were compared with the Student $t$ test for paired observations (PMV baseline vs dobutamine) and independent observations (control vs PMV).

\section{Results \\ Surgical Outcome}

Seven of the 22 animals that underwent implantation of the PMV xenograft survived beyond 24 hours. Of the 15 deaths, 6 were caused by early pulmonary failure, 2 were caused by bleeding, 1 was caused by a stroke, and 1 was caused by
TABLE 2. PMV hemodynamics with dobutamine

\begin{tabular}{lccc}
\hline & Baseline & Dobutamine & $P$ value \\
\hline $\mathrm{HR}$ (beats/min) & $109 \pm 20$ & $138 \pm 14$ & .006 \\
$\mathrm{dP} / \mathrm{dt}_{\text {max }}(\mathrm{mm} \mathrm{Hg})$ & $1322 \pm 397$ & $2452 \pm 766$ & .002 \\
$\mathrm{LVP}_{\max }(\mathrm{mm} \mathrm{Hg})$ & $108 \pm 9$ & $134 \pm 17$ & .006 \\
$\mathrm{EDV}(\mathrm{mL})$ & $176 \pm 25$ & $174 \pm 25$ & .12 \\
$\mathrm{ESV}(\mathrm{mL})$ & $137 \pm 15$ & $128 \pm 15$ & .005 \\
$\mathrm{CO}(\mathrm{L} / \mathrm{min})$ & $4.5 \pm 1.3$ & $7.0 \pm 1.4$ & .0001
\end{tabular}

Data are shown as mean \pm SD. $P$ value by means of $t$ test for paired observations.

$H R$, Heart rate; $d P / d t_{M A X}$ maximum positive rate of change of $L V$ pressure; $L V P_{\text {MAX, }}$ maximum systolic LV pressure; EDV, LV end-diastolic volume; $E S V$, LV end-systolic volume; $\mathrm{CO}$, cardiac output.

premature self-extubation. Five of the deaths were directly related to technical aspects of implantation. Three animals died of leaflet prolapse and severe mitral regurgitation (MR; technical errors) when the PM sewing tubes were not inserted apically enough. The 2 other valve-related deaths were due to annular dehiscence near the anterior commissure in one animal and posterior PM sewing tube dehiscence in another, causing severe MR. There was a considerable learning curve (no survivors in the first 10 attempted implantations, but 7 of 12 survivors subsequently); this was primarily due to a lower incidence of respiratory failure, which was linked to shortening the CPB time and using aprotinin for its putative lung protective and anti-inflammatory effects. The CPB and aortic crossclamp times for the first 10 animals were $130 \pm 23$ and $87 \pm 15$ minutes, respectively, but fell to $96 \pm 13$ and $64 \pm 6$ minutes in the last 12 animals. Mean aortic crossclamp time for the surviving 7 PMV animals who were cathetherized did not differ from that of the 8 control animals $(64 \pm 8$ vs $61 \pm 3$ minutes, $P=.4$ ), although their total CPB time was somewhat longer ( $93 \pm 11$ vs $82 \pm 5$ minutes, $P=.04)$. There was no difference in weight between the 2 groups (76 \pm 14 and $76 \pm 9 \mathrm{~kg}$ for PMV and control groups, respectively; $P=.9)$.

\section{Hemodynamics}

Table 1 summarizes the hemodynamics of control and PMV animals during baseline conditions. There was no significant difference between the groups in heart rate, $\mathrm{LV} \mathrm{dP/dt}$, peak LV pressure, end-systolic and end-diastolic volumes, or stroke volume. These data indicate comparable loading and hemodynamic conditions between the 2 groups, thus allowing direct comparison of valvular performance and dynamics. Hemodynamic variables before and after dobutamine infusion in the PMV animals are shown in Table 2, and these indicated a markedly enhanced inotropic state. Cardiac output increased by $61 \%$ during dobutamine infusion, which allowed assessment of valvular hemodynamics and leaflet 3-D motion during high flow conditions. 


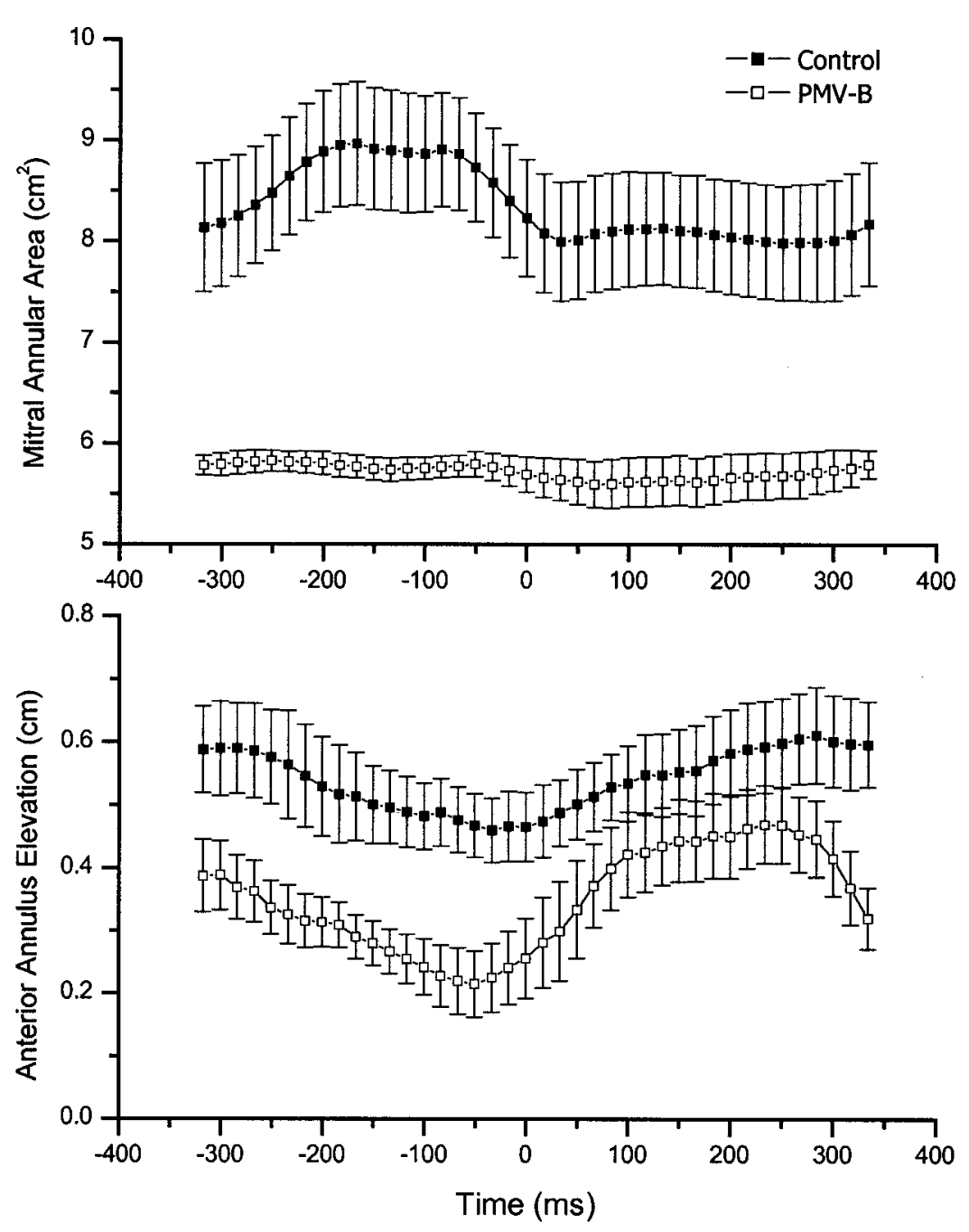

Figure 2. Group mean MAAs (in square centimeters, top panel) and septal anulus elevation (in centimeters, bottom pane/) throughout the cardiac cycle for control animals (filled squares) and PMV animals (open squares). Data are centered at end-diastole $(t=0)$, with a 650 -ms time window shown. Error bars equal 1 SEM.

\section{Echocardiographic Evaluation}

The Doppler mean and peak valvular gradients across the PMV immediately after weaning from CPB (open-chest epicardial imaging) were $2.4 \pm 1.2$ and $4.4 \pm 2.1 \mathrm{~mm} \mathrm{Hg}$, respectively. At an average of 10 days postoperatively (closed-chest imaging), the transesophageal echocardiographic Doppler mean and peak gradients were $3.6 \pm 1.3$ and $6.6 \pm 0.9 \mathrm{~mm} \mathrm{Hg}$ during baseline conditions and increased to $6.2 \pm 2.2 \mathrm{~mm} \mathrm{Hg}(P=.01)$ and $9.8 \pm 5.3 \mathrm{~mm}$ $\mathrm{Hg}(P=.14)$ during dobutamine infusion. In 1 animal a reliable gradient could not be obtained during dobutamine infusion because of echocardiographic technical difficulties. Analysis of leaflet motion revealed good leaflet opening and mobility of the anterior PMV leaflet but very limited motion of the posterior leaflet. Color Doppler imaging showed MR to be absent in 1 animal, trace in 1 animal, mild in 3 animals, moderate in 1 animal, and moderate to severe in another animal, yielding an average MR grade of $1.2 \pm 1.0$. The moderate MR in 1 animal was a result of placing papillary sewing tubes apically too far apart, resulting in leaflet restriction, whereas the animal with moderate-tosevere MR had only trace insufficiency immediately postoperatively but subsequently had a large perivalvular leak.

\section{Mitral Annular Dynamics}

MAA and elevation of the septal (anterior) anulus above the lateral annular plane throughout the cardiac cycle for control and PMV animals are shown in Figure 2. After implantation, the motion of the stentless PMV mitral xenograft anulus was reduced, with only a $6 \%$ MAA change throughout the cardiac cycle (Table 3 ). This was most likely related to the significant reduction of maximum MAA by $35 \%(P=$ 
TABLE 3. Mitral annular and leaflet dynamics

\begin{tabular}{lccl}
\hline & Control & PMV & P value \\
\hline MAA $_{\text {MAX }}\left(\mathrm{cm}^{2}\right)$ & $9.06 \pm 1.59$ & $5.89 \pm 0.25$ & .0002 \\
MAA $_{\text {MIN }}\left(\mathrm{cm}^{2}\right)$ & $7.90 \pm 1.51$ & $5.54 \pm 0.56$ & .01 \\
$\Delta M^{2}(\%)$ & $13.0 \pm 4.0$ & $6.0 \pm 6.3$ & .001 \\
$M_{\text {FLEX }}(\mathrm{cm})$ & $0.14 \pm 0.08$ & $0.21 \pm 0.10$ & .1 \\
$\mathrm{~L}_{\mathrm{AML}}(\mathrm{cm})$ & $2.21 \pm 0.34$ & $2.75 \pm 0.28$ & .008 \\
$\mathrm{~L}_{\mathrm{PML}}(\mathrm{cm})$ & $1.28 \pm 0.14$ & $2.16 \pm 0.37$ & .0003 \\
$\Delta \theta_{\mathrm{AML}}\left({ }^{\circ}\right)$ & $48 \pm 8$ & $41 \pm 19$ & .3 \\
$\Delta \theta_{\mathrm{PML}}\left({ }^{\circ}\right)$ & $34 \pm 12$ & $10 \pm 2$ & .0001 \\
\hline
\end{tabular}

Data are shown as mean \pm SD. $P$ value by means of $t$ test for independent observations.

$M A A_{M A X}$, Maximum mitral annular area; $M A A_{M I N}$, minimum mitral annular area; $\triangle M A A$, change in mitral annular area from maximum to minimum; $M A_{F L E X}$ change in the orthogonal distance from the mid septalanulus to the posterior annular plane during systole; $L_{A M L}$, anterior mitral leaflet length; $L_{P M L}$ posterior mitral leaflet length; $\Delta \theta_{A M L^{\prime}}$ anterior leaflet excursion angle from maximum to minimum; $\Delta \theta_{P M L}$, posterior mitral leaflet excursion angle from maximum to minimum.

.002), resulting from suturing the PMV around the mitral anulus, similar to an annuloplasty ring effect. However, folding of the septal anulus, defined as the change in distance of the midseptal marker to the posterior annular plane during systole, was similar in the 2 groups, suggesting that annular flexibility or folding was maintained with the PMV valve. The 3-D geometric relationship between the mitral anulus and the PMs in the control and the PMV study animals are shown in Figure 3. Although annular shape was similar, the PMV PM sewing tubes were inserted closer to the septum because of the natural $180^{\circ}$ orientation of the PMV (porcine) PMs compared with the angle between the native ovine $\mathrm{PM}$ positions.

\section{Mitral Leaflet 3-D Dynamic Motion}

Angular excursion of the AMLs and PMLs throughout the entire cardiac cycle in the control and the PMV animals are shown in Figure 4 and Table 3. The anterior PMV leaflet remained very mobile, with total excursion throughout the cardiac cycle similar to that observed in the control animals. The posterior PMV leaflet, however, was almost completely frozen, with an angular excursion of only $10^{\circ}$ from maximum to minimum during the cardiac cycle. Figure 5 shows a 2-D reconstruction of leaflet shape during valve closure in both groups. The posterior leaflet of the xenograft had very limited mobility, and the anterior leaflet had a convex shape toward the atrium throughout closure compared with the more concave shape of the anterior leaflet in the control sheep. Some billowing of the basal portion of the anterior PMV leaflet was observed, most likely caused by redundancy of PMV leaflet tissue. The distance between the anterior leaflet edge marker and the annular plane (leastsquares fit of all 8 annular markers) at end-systole did not differ between the control and PMV animals $(0.75 \pm 0.19$ vs $1.12 \pm 0.59 \mathrm{~cm}$ for control and PMV, respectively; $P=$ .14). The distance between the posterior PMV leaflet edge marker and the anulus, however, was longer (displaced apically) at end-systole relative to that of the control animals $(1.69 \pm 0.61$ vs $0.75 \pm 0.12 \mathrm{~cm}$, respectively; $P=$ .002 ) as a result of limited leaflet mobility, malpositioning, or both of the PM sewing tube.

\section{Follow-up}

Four of the 5 animals survived more than 3 months. One animal died at 3 weeks postoperatively as a result of right heart failure. Of the four 3-month survivors, one animal died of a cerebral embolus after 3 months, and one had endocarditis. Gross examination of these 4 hearts revealed good healing and limited pannus formation around the PM sewing tube insertion sites, with firm fixation to the LV wall. The anulus was well endothelialized (Figure 6), and there was normal-appearing pliability of the mitral leaflets (except in the animal with endocarditis, which had vegetations and calcification of the valve).

\section{Discussion}

Stentless mitral bioprostheses have spurred renewed clinical interest $^{12,23,24}$ because the durability and performance of stented bioprostheses are suboptimal in the mitral position. ${ }^{25,26}$ Compared with mitral homografts, porcine mitral xenografts offer the advantage of more consistent subvalvular anatomy and widespread availability. Although they have been introduced into clinical practice, ${ }^{13,27}$ their clinical efficacy is uncertain. In this experiment the Medtronic PMV had reasonable valvular competence, low transvalvular pressure gradients at rest, and acceptable transvalvular gradients during inotropic stimulation 10 days after implantation. There was little dynamic area change of the PMV mitral anulus, and posterior leaflet motion was limited; mitral annular folding and anterior leaflet excursion were comparable with that seen in the control animals' native ovine valves. This study extended our preliminary, acute nonsurvival evaluation of an earlier version of this bioprosthesis ${ }^{18}$; analysis of leaflet motion, annular folding, and PM tip position 10 days postoperatively was included in the current experiment.

\section{Surgical Technique}

Technically, satisfactory implantation of mitral homograft and xenograft valves presents a new surgical challenge, and considerable experience is required to achieve good results. ${ }^{17}$ In our experiment most of the deaths early on resulted from pulmonary failure. Sheep lungs do not tolerate prolonged periods of $\mathrm{CPB}$; pulmonary deaths were rare after we shortened the CPB times and started using aprotinin. On the other hand, 5 deaths were directly related to technical errors, mostly related to not inserting the PM sewing tubes 


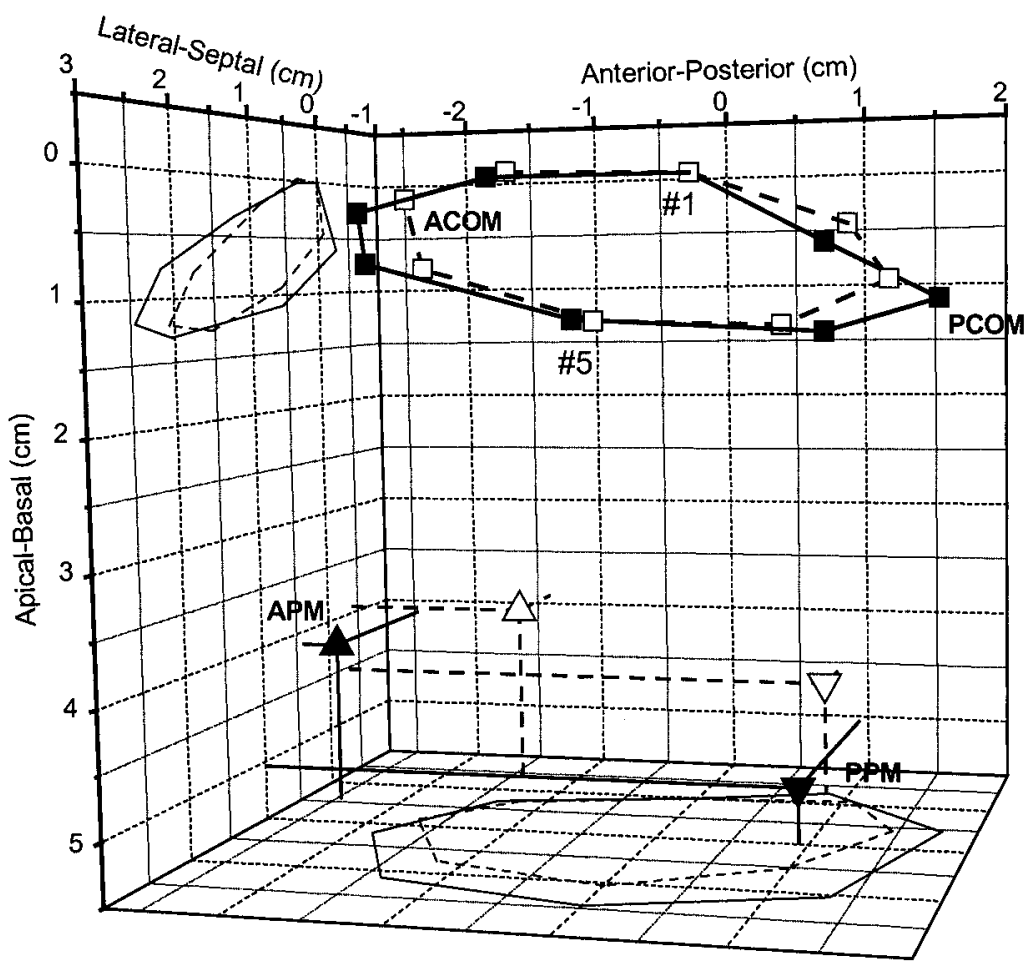

Figure 3. Group mean data for the 3-D reconstruction of the mitral anulus (squares) and PM tips (triangles) in control (filled symbols) and PMV (open symbols) animals. Drop lines in all 3 planes (PMs only) are shown for clarity. Midseptal (1) and midlateral (5) annular markers are labeled for orientation. ACOM, Anterior commissure; PCOM, posterior commissure; APM, anterior PM; PPM, posterior PM.

apically enough. Because the porcine mitral valve has leaflets of almost equal height and longer chordae than the ovine valve, the PM heads, particularly the posterior PM head, must be implanted apically distant relative to the native ovine PM tips to avoid PMV leaflet prolapse. Because the ovine ventricle is conical in shape and thick walled, proper implantation of the PM sewing tubes is difficult because of limited visibility deep in the left ventricle. Furthermore, because of the $180^{\circ}$ positioning of the porcine PM heads relative to the long axis of the ventricle, the PM sewing tubes of the PMV cannot be simply implanted on the recipient's native PM tips; in this preparation they ended up being inserted closer to the septal anulus (Figure 3) to avoid twisting of the subvalvular apparatus. Size mismatch between the native and xenograft mitral anulus, on the other hand, proved to be less problematic and could be corrected by means of annular plication without obvious compromise of valve function. This resulted, however, in a substantial cinching effect on the mitral anulus, which dampened its 3-D motion, similar to what is seen after mitral ring annuloplasty in experimental animals. ${ }^{28}$ Although there was a considerable learning curve for us, we found that with experience, the PMV valve can be im- planted in a predictable and reproducible fashion with clinically acceptable CPB and aortic crossclamp times.

Previous experimental studies with stentless ovine allografts in growing sheep revealed that early valve failure was related to chordal rupture or technical error in PM implantation. ${ }^{29}$ In patients with an implanted porcine stentless mitral xenograft, the high rate of valve failure and recurrent mitral insufficiency were due to valve tissue tears parallel to the mitral anulus, particularly on the posterior aspect of the anulus and near the commissures. ${ }^{30}$ These findings were often accompanied by chordal rupture, suggesting excessive tension on the chordal apparatus, possibly related to the technical aspect of PM implantation. Chordal tears and PM disruption caused by improper PM implantation have also been reported in human mitral allografts, ${ }^{14,15}$ which could also occur with PMV implantation. We did not observe any ruptured chordae, but 4 deaths were directly related to technical errors in PM implantation.

\section{Valvular 3-D Dynamics and Leaflet Motion}

As reported in prior clinical ${ }^{12,23,24}$ and experimental $18,29,31$ studies of stentless mitral valves, the baseline mean and peak gradients across the PMV were low. There is a paucity 


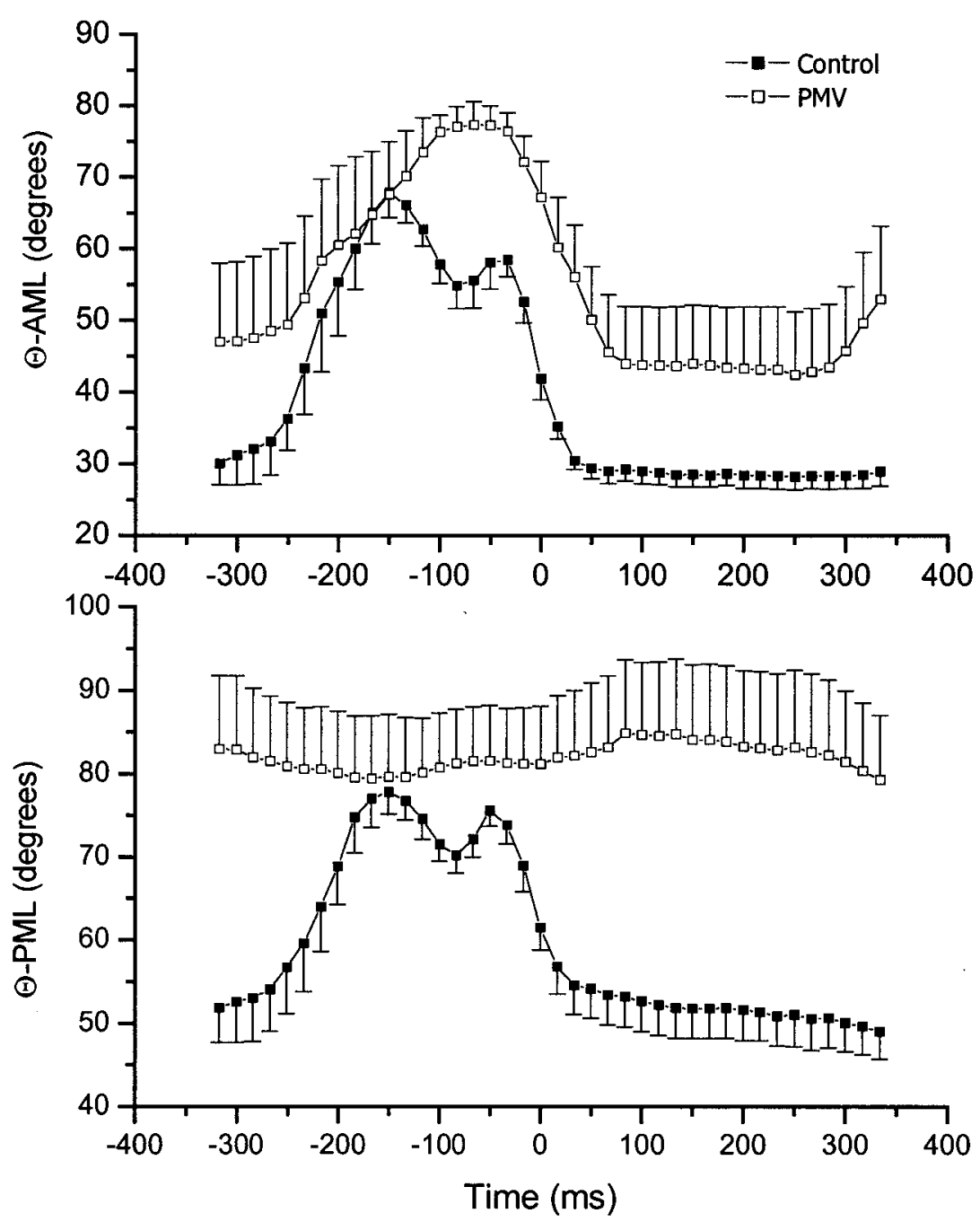

Figure 4. Group mean data for angular displacement of anterior (top panel) and posterior (bottom panel) mitral leaflet edge angle throughout the cardiac cycle for native mitral leaflets (filled symbols) and PMV leaflets (open symbols). Data are centered at end-diastole $(\mathrm{t}=0)$, with a 650 -ms time window displayed. Error bars indicate 1 SEM. Note the cyclic motion of $\varphi_{\mathrm{AML}}$ but essentially fixed value of $\varphi_{\mathrm{PML}}$ in the PMV animals.

of data on the hemodynamic performance of stentless mitral bioprostheses under high flow conditions; this experiment revealed acceptable mean gradients across the PMV xenograft in the face of a $67 \%$ increase in cardiac output. For perspective $^{32-35}$ (even though direct comparisons between human subjects and animals are difficult), the mean transvalvular gradient in the PMV animals during inotropic stimulation and high flow conditions was only $1 \mathrm{~mm} \mathrm{Hg}$ higher than the average gradient of a quadrileaflet stentless mitral bioprosthesis in human subjects. ${ }^{36}$

Although no clinical data exist at the present time, it is postulated that the superior hemodynamic performance of stentless mitral bioprostheses might, in large part, be related to maintained normal annular motion. Surprisingly, dynamic MAA change was damped after PMV implantation in the current study, which was different than that observed in our earlier acute, open-chest experiment. ${ }^{18}$ This discordance might be due to the previous animals being relatively hyperdynamic and receiving inotropic drugs immediately postoperatively because of the differences in the experimental conditions (open-chest and anesthetized vs closed-chest and sedated conditions) or perhaps because of a greater reduction of MAA and more of an annular purse-string effect in the current PMV series. Similar degrees of MAA reduction (approximately 30\%-35\%) after flexible ring annuloplasty have also been shown to abolish mitral annular dynamics in sheep. ${ }^{28}$ Folding of the septal anulus in the PMV xenograft was similar to that in the native ovine anulus; preservation of normal annular folding might be important for avoiding LV outflow tract obstruction after 


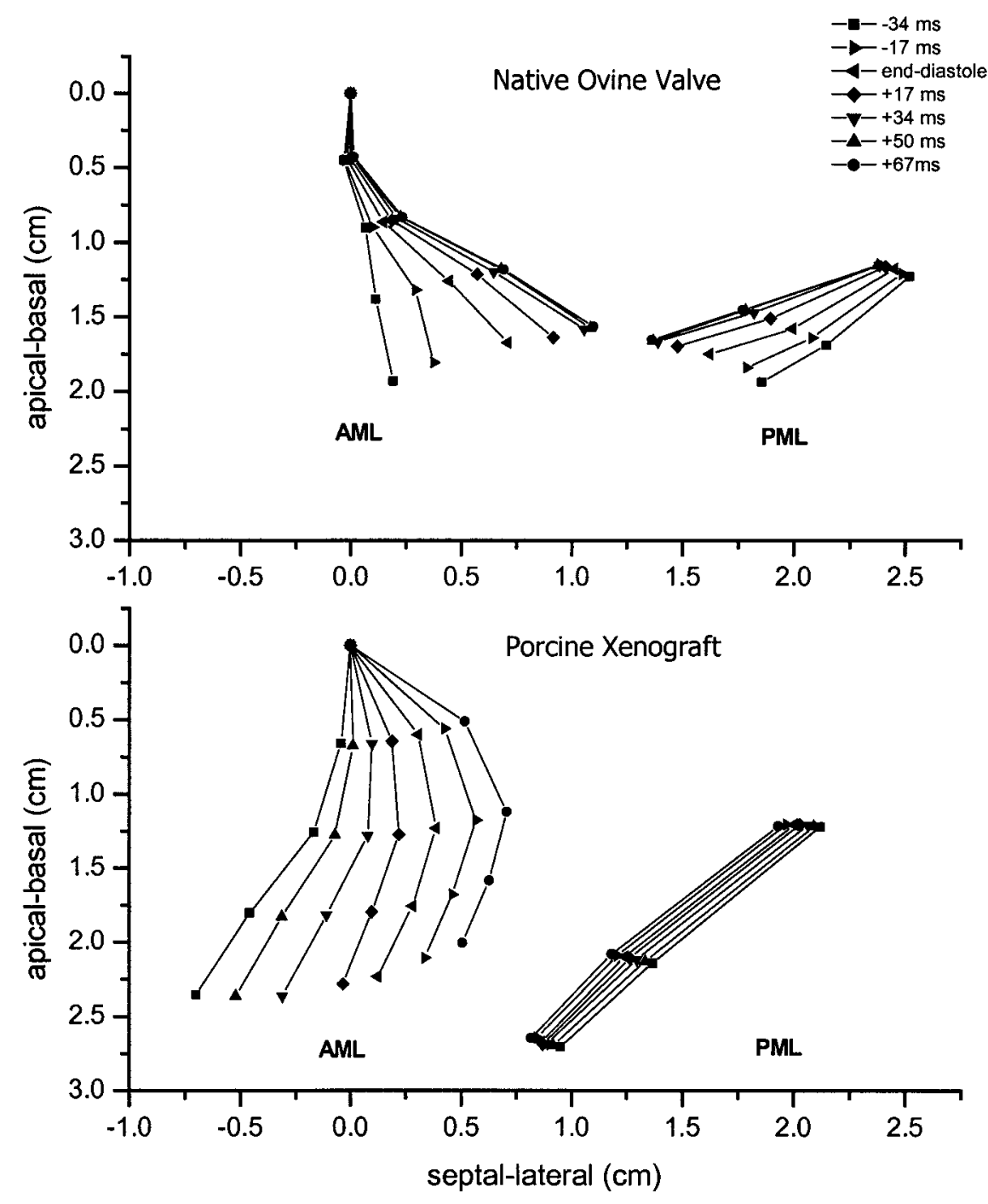

Figure 5. Two-dimensional reconstruction of mitral leaflet shape during valve closure (from $34 \mathrm{~ms}$ before end-diastole to $67 \mathrm{~ms}$ after end-diastole) in the native ovine valve (top panel) and the porcine mitral xenograft (bottom panel). Each reconstruction represents mean data from 5 animals at each time point.

annular reduction, ${ }^{37}$ particularly with the relatively large amount of tissue in the anterior leaflet of the PMV bioprosthesis.

This porcine xenograft functioned effectively as a monoleaflet valve in vivo, with a frozen posterior leaflet acting as a buttress against which the AML closed. The PMV anterior leaflet was concave to the left atrium during closure, with some relative billowing of the basal portion of the leaflet, which was different from the closing motion of the native ovine leaflet. Whether this altered shape reflects abnormal chordal forces, which could in turn affect leaflet durability and function, is unclear; however, displacement of the PMV anterior leaflet edge away from the annular plane did not differ from that of control hearts, indicating appropriate restoration of the valvular-subvalvular geometric relationship. Whether limited posterior leaflet motion is related to reduction of annular size, change in the annular-papillary distance, or both is speculative, but frozen posterior leaflet motion has been observed in ovine hearts after annular reduction with either a flexible or a semirigid annuloplasty ring $^{38}$ and also seen commonly in patients after a mitral ring annuloplasty. Perhaps both annular dynamics and posterior leaflet motion might be less abnormal if these valves had been oversized, as is done with mitral homografts clinically. ${ }^{12,15}$

Although 3 months' follow-up is short, and there were only 4 animals, the preliminary pathologic findings were encouraging. Excluding the animal that had endocarditis, 


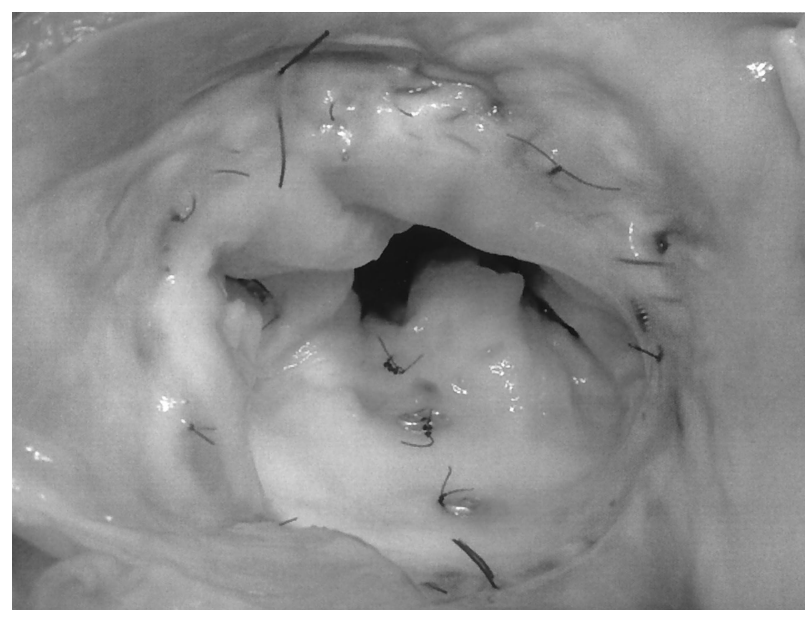

Figure 6. Postmortem atrial view of the PMV valve 4 months after implantation. The PMV annular sewing ring is well endothelialized and completely incorporated into the native mitral anulus. AML with implanted markers is visible through the PMV orifice.

the PMV anulus was completely endothelialized and well incorporated into the native mitral anulus. The leaflets were pliable, with only minimal calcification, and the PM sewing tubes were covered with fibrous tissue and firmly attached to the LV wall.

\section{Limitations}

Leaflet dynamics of the porcine xenograft were compared with those of the native ovine valve, and the observed differences might not only be related to technical aspects of implantation but also to possible interspecies differences in porcine and ovine mitral valve closing mechanics in vivo. Radiopaque marker studies require suturing of small markers on leaflets, which could potentially affect normal leaflet motion, but both groups of animals had the same kind of leaflet markers placed in identical arrays. Therefore, any effects of the composite mass of the markers should be the same. Furthermore, it is unlikely that the markers interfered with mitral leaflet motion because they are very small (aggregate mass, $20 \pm 6 \mathrm{mg}$ ). Even when we grossly overloaded the anterior leaflet with a very large number of excessively heavy markers (total mass, $184 \mathrm{mg}$ ) in another study, the peak anterior leaflet opening velocity determined by means of epicardial PW Doppler echocardiography was $0.47 \pm 0.05 \mathrm{~m} / \mathrm{s}$ compared with $0.45 \pm 0.06 \mathrm{~m} / \mathrm{s}$ for leaflets without any markers attached. We placed markers only on the central portion of each leaflet, and therefore no data on leaflet shape and dynamics in the commissural parts of the leaflets are available. Lack of preoperative sizing of the xenograft and having available a complete set of all sizes of PMV bioprostheses is another possible limitation; in certain cases we were forced to implant a valve that obviously was too long or too large for a particular sheep's ventricle. More refined PMV sizing methods (incorporating both mitral annular size and the length of the LV chamber) and availability of more sizes will provide better surgical results.

We appreciate the technical assistance provided by Mary K. Zasio, BA, Carol W. Mead, BA, and Maggie Brophy, AS.

\section{References}

1. Rastelli GC, Tsakiris AG, Banchero N, Wood EH, Kirklin JW. Cardiac performance after replacement of the dog mitral valve with Starr-Edwards prosthesis with and without preservation of the chordae tendineae. Surg Forum. 1966;17:178-9.

2. Hubka M. Homotransplantation of the cardiac valves. Folia Biol. 1965;11:324-7.

3. Hubka M, Siska K, Brozman M, Holec V. Replacement of mitral and tricuspid valves by mitral homograft. J Thorac Cardiovasc Surg. 1966;51:195-204.

4. Senning A. Rekonstruktion der Mitralklappe: Homoioplastik. Thoraxchir Vask Chir. 1968;16:601-5.

5. Yacoub MH, Kittle CF. A new technique for replacement of the mitral valve by a semilunar valve homograft. $J$ Thorac Cardiovasc Surg. 1969;58:859-69.

6. Carpentier A. Cardiac valve surgery-the "French correction." J Thorac Cardiovasc Surg. 1983;86:323-37.

7. Acar C, Gaer J, Chauvaud S, Carpentier A. Technique of homograft replacement of the mitral valve. J Heart Valve Dis. 1995;4:31-4.

8. Bodnar E. Clinical use of homologous and heterologous mitral valves [editorial]. J Heart Valve Dis. 1994;3:468-9.

9. Duran CM. Mitral valve allografts. An opportunity [editorial]. J Heart Valve Dis. 1995;4:29-30.

10. Hansen DE, Cahill PD, Derby GC, Miller DC. Relative contributions of the anterior and posterior mitral chordae tendineae to canine global left ventricular systolic function [published erratum appears in $J$ Thorac Cardiovasc Surg. 1987;93:793]. J Thorac Cardiovasc Surg. 1987; 93:45-55.

11. Sarris GE, Miller DC. Valvular-ventricular interaction: the importance of the mitral chordae tendineae in terms of global left ventricular systolic function. J Card Surg. 1988;3:215-34.

12. Acar C, Tolan M, Berrebi A, Gaer J, Gouezo R, Marchix T, et al. Homograft replacement of the mitral valve. Graft selection, technique of implantation, and results in forty-three patients. $J$ Thorac Cardiovasc Surg. 1996;111:367-80.

13. Vrandecic MO, Fantini FA, Gontijo BF, Oliveira OC, Martins IC, Oliveira MH, et al. Surgical technique of implanting the stentless porcine mitral valve. Ann Thorac Surg. 1995;60:S439-42.

14. Yankah AC, Sievers HH, Lange PE, Bernhard A. Clinical report on stentless mitral allografts. J Heart Valve Dis. 1995;4:40-4.

15. Kumar AS, Choudhary SK, Mathur A, Saxena A, Roy R, Chopra P. Homograft mitral valve replacement: five years' results. $J$ Thorac Cardiovasc Surg. 2000;120:450-8.

16. Victor S, Nayak VM. Variations in the papillary muscles of the normal mitral valve and their surgical relevance. J Card Surg. 1995;10:597607.

17. Acar C. Mitral valve homograft. Adv Card Surg. 1997;9:1-13.

18. Dagum P, Green GR, Timek TA, Daughters GT, Foppiano LE, Tye TL, et al. Functional evaluation of the Medtronic stentless porcine xenograft mitral valve in sheep. Circulation. 1999;100:II70-7.

19. Girardot MN, MacDonald M, Duarte I, Brown WM, Girardot JM.Advances in anticalcific and antidegenerative treatment of heart valve bioprostheses. Austin, TX: Silent Partners, Inc; 1997.

20. Glasson JR, Komeda MK, Daughters GT, Niczyporuk MA, Bolger $\mathrm{AF}$, Ingels NB, et al. Three-dimensional regional dynamics of the normal mitral annulus during left ventricular ejection. $J$ Thorac Cardiovasc Surg. 1996;111:574-85.

21. Daughters GT, Miller DC, Schwartzkopf A, Mead CW, Ingels NB. A comparison of two analytical systems for three-dimensional reconstruction from biplane video radiograms. IEEE Proc Comp Cardiol. $1988 ; 15: 79-82$. 
22. Moon MR, DeAnda A, Daughters GT, Ingels NB, Miller DC. Experimental evaluation of different chordal preservation methods during mitral valve replacement. Ann Thorac Surg. 1994;58:931-44.

23. Gulbins H, Kreuzer E, Uhlig A, Reichart B. Mitral valve surgery utilizing homografts: early results. J Heart Valve Dis. 2000;9:222-9.

24. Walther T, Walther C, Falk V, Diegeler A, Krakor R, Schneider J, et al. Early clinical results after stentless mitral valve implantation and comparison with conventional valve repair or replacement. Circulation. 1999; 100:II78-83.

25. Fann JI, Miller DC, Moore KA, Mitchell RS, Oyer PE, Stinson EB, et al. Twenty-year clinical experience with porcine bioprostheses. Ann Thorac Surg. 1996;62:1301-12.

26. Bernal JM, Rabasa JM, Lopez R, Nistal JF, Muniz R, Revuelta JM. Durability of the Carpentier-Edwards porcine bioprosthesis: role of age and valve position. Ann Thorac Surg. 1995;60:S248-52.

27. Vrandecic M, Gontijo BF, Fantini FA, Oliveira OC, Martins IC, Oliveira $\mathrm{MH}$, et al. Porcine stentless mitral heart valve substitute: short term clinical data. J Cardiovasc Surg (Torino). 1994;35:41-5.

28. Glasson JR, Green GR, Nistal JF, Dagum P, Komeda M, Daughters GT, et al. Mitral annular size and shape in sheep with annuloplasty rings. J Thorac Cardiovasc Surg. 1999;117:302-9.

29. Vetter HO, Dagge A, Liao K, Erhorn A, Chryssagis K, Strenkert C, et al. Mitral allograft with chordal support: echocardiographic evaluation in sheep. J Heart Valve Dis. 1995;4:35-9.

30. Morea M, De Paulis R, Galloni M, Gastaldi L, di Summa M. Mitral valve replacement with the Biocor stentless mitral valve: early results. J Heart Valve Dis. 1994;3:476-82.

31. Vetter H, Nerlich A, Welsch U, Liao K, Dagge A, Strenkert C, et al. Total replacement of the mitral apparatus with a stentless, chordally supported mitral valve allograft: an experimental study. J Thorac Cardiovasc Surg. 1996;111:595-604.

32. Ormiston JA, Shah PM, Tei C, Wong M. Size and motion of the mitral valve annulus in man. I. A two-dimensional echocardiographic method and findings in normal subjects. Circulation. 1981;64:113-20.

33. Pai RG, Tanimoto M, Jintapakorn W, Azevedo J, Pandian NG, Shah PM. Volume-rendered three-dimensional dynamic anatomy of the mitral annulus using a transesophageal echocardiographic technique. J Heart Valve Dis. 1995;4:623-7.

34. Glasson JR, Komeda M, Daughters GT, Foppiano LE, Bolger AF, Tye TL, et al. Most ovine mitral annular 3-D size reduction occurs before ventricular systole and is abolished with ventricular pacing. Circulation. 1997;96:II115-23.

35. Walmsley R. Anatomy of human mitral valve in adult cadaver and comparative anatomy of the valve. Br Heart J. 1978;40:351-66.

36. Hofman B, Knaut M, Kappert U, Tugtekin SM, Aron W, Schuler S. Early experience with a quadrileaflet stentless mitral valve. Ann Thorac Surg. 2001;7:S323-6.

37. Dagum P, Green GR, Glasson JR, Daughters GT, Bolger AF, Foppiano LE, et al. Potential mechanism of left ventricular outflow tract obstruction after mitral ring annuloplasty. J Thorac Cardiovasc Surg. 1999; 117:472-80.

38. Green GR, Dagum P, Glasson JR, Nistal JF, Daughters GT, Ingels NB, et al. Restricted posterior leaflet motion after mitral ring annuloplasty. Ann Thorac Surg. 1999;68:2100-6.

\section{Discussion}

Vaughn Starnes (Los Angeles, Calif). This is yet another in a continuing series of the mitral valve studies ongoing at Stanford, and we owe a great deal of gratitude to the group.

This is a very complex model, and I admire your surgical tenacity with the first 10 preparations dying. I think we can attribute that to the effects of putting a sheep on CPB and the lung damage that it will do, but I think we have to focus also on the 5 deaths that seem to be the result of technical problems. All the PMV animals were studied at 10 days, and I would like to focus on 3 points of the study: valve gradient, valve function, and valve motion.
I think points about durability can not be surmised from this study, although we did note there was some early calcification in some of these valves, as you pointed out in your article. As we look at valve gradient, we see minimal gradient, an average of about $3 \mathrm{~mm}$ during the control state, 6 peak gradients, and again on dobutamine infusion, it only rose to about twice that, or $6 \mathrm{~mm}$. Now we look at valvular function, and this is going to lead to my first question: Of the valves studied-these were 7 valves-we have had 1 valve with no leak, 1 valve with $1+, 3$ valves with $2+$, 1 valve with $3+$, and 1 valve with $4+$, and you mean those to a score of 1.2, and you said that on the basis of these data, you believed you had only mild regurgitation as a group. Could you comment on that? It would seem to me that if you average those out, we would probably rate most of those valves in the mild-tomoderate regurgitation group.

Dr Timek. The data in the article were on the first 5 valves, 1 with no regurgitation, 1 with trace regurgitation, and 3 with mild regurgitation. Of the 2 subsequent animals that were added, there was one with moderate and one with moderate-to-severe regurgitation. According to that scale, it was 1.2.

Dr Starnes. Another question I have, obviously, in doing this operation is that we had a lot of technical difficulties in the beginning, and then we ended up with 7 survivors. Could you tell us whether you learned during this preparation how to determine the length of the chordal attachments. It seemed to be the most difficult part of this operation.

Dr Timek. Thank you. That is a very insightful point. Indeed, that is the most difficult part of this operation, to decide how deep the papillary tips must be placed. Initially, we began by placing them as far apically as possible, and in sheep with normal ventricles, that did not seem to be a wrong thing to do. We also tried to measure them with a custom-designed tape, and that has also helped us. One of the problems that we have had is that because of the valve availability, we cannot always match the size of the valve with the size of the sheep, and therefore it is somewhat subjective where the papillary tip is placed. We are currently still working on how to refine that technique because that has really been the major portion of our technical failures, where the papillary muscle tips are placed.

Dr Starnes. With the sheep's heart being more conical than elliptical, would you anticipate the implantation in the human subject to be easier?

Dr Timek. We would like to think so; however, at this point, we can not comment on that, although it would seem reasonable that in a dilated ventricle, where you could excise the entire valve, you probably would have good exposure, and perhaps it would be easier to implant these valves. However, that is all wishful thinking.

Dr Starnes. I would like to turn now to the leaflet motion. Again, because of the excellent technical capabilities of the laboratory, you were able to follow the physiologic motion of the anterior and posterior leaflets. The results revealed a mobile anterior leaflet and a fixed posterior leaflet. This brings me to my second question. Do you believe the immobile posterior leaflet was due to chordal positioning, or do you believe it is due to the retained posterior leaflet and chordae apparatus that I noticed you left in these animals? In other words, you did not excise the 
posterior leaflet. Could that have been the effect of your immobile leaflet posteriorly?

Dr Timek. That is a very good question. The reason for leaving the posterior leaflet in is to provide extra tissue to sew the PMV valve because the ovine mitral anulus is rather fine. In terms of freezing the posterior leaflet, we have seen that with any type of annular reducing procedure, such as a ring annuloplasty, either a flexible or rigid anulus, when we reduce the annular size, we also freeze the PML. In this experiment you see that for weightmatched animals, the anulus is reduced by about $30 \%$ in the PMV valves, and that is approximately what we see with annuloplasty rings. We believe that one reason why the posterior leaflet is frozen is because of the annular reduction. Of course, the second possible and likely reason is the placement of the papillary muscle tips. How to differentiate those is difficult to say, but we suspect that both contribute. 